\title{
Mulheres negras e a violência obstétrica: uma revisão integrativa
}

\author{
Black woman and the obstetric violence: an integrative review \\ Las mujeres negras y la violencia obstétrica: una revisión integradora
}

Recebido: 28/12/2021 | Revisado: 03/01/2022 |Aceito: 08/01/2022 | Publicado: 11/01/2022

\author{
Juliana Lana Querino de Oliveira \\ ORCID: https://orcid.org/0000-0002-0472-7480 \\ Universidade Veiga de Almeida, Brasil \\ E-mail: jlquerino@hotmail.com \\ Abilene do Nascimento Gouvêa \\ ORCID: https://orcid.org/0000-0002-3033-5069 \\ Universidade Veiga de Almeida, Brasil \\ E-mail: abilenegouvea@gmail.com \\ Marcos José Vilchez David \\ ORCID: https://orcid.org/0000-0002-8794-1473 \\ Universidade Veiga de Almeida, Brasil \\ E-mail: marcosjvdavid@gmail.com
}

\begin{abstract}
Resumo
Objetivo: Identificar a relação do racismo institucional com a violência obstétrica em mulheres negras. Metodologia: Trata-se de uma revisão integrativa de literatura que seguiu a seis etapas indicadas para sua execução: seleção do tema e elaboração da pergunta norteadora; busca na literatura; coleta de dados; análise dos estudos incluídos; discussão do resultado e apresentação da revisão integrativa, os resultados relacionados à pesquisa, foram reunidos de maneira sistemática e ordenada. Resultados: Apontaram para existência de uma maior vulnerabilidade das mulheres negras na assistência obstétrica, sendo elas mais suscetíveis a sofrer violência obstétrica em decorrência do racismo institucional instalado na sociedade, que é consequência do histórico escravocrata do país tendo até os dias atuais seus resquícios.
\end{abstract}

Palavras-chave: Saúde da Mulher; Enfermagem Obstétrica; Violência contra a Mulher; Racismo; Violência Obstétrica.

\begin{abstract}
Objective: Identifying the relationship between institutional racism and obstetric violence in black women. Methodology: This is an integrative literature review that followed six steps indicated for its implementation: topic selection and elaboration of the guiding question; literature search; data collect; analysis of included studies; discussion of the result and presentation of the integrative review, the research related results were gathered in a systematic and orderly manner. Results: Pointed to the existence of a greater vulnerability of black women in obstetric care, as they are more susceptible to suffering obstetric violence as a result of the institutional racism installed in society, which is a consequence of the country's slavery history, which remnants to this day.

Keywords: Women's Health; Obstetric Nursing; Violence against Women; Racism; Obstetric Violence.

Resumen

Objetivo: Identificar la relación del racismo institucional con la violencia obstétrica en mujeres negras. Metodología: Se trata de una revisión integradora de literatura que ha surgido en seis pasos para la ejecución: selección del tema y elaboración de la pregunta; busca en literatura; recolección de datos; análisis de los estudios inclusos; discusión del resultado y presentación de revisión integradora, los resultados vinculados para ejecución de la pesquisa, ha reunido de manera sistemática y ordenada. Resultados: señalaron para la existencia de una mayor vulnerabilidad de las mujeres negras en la atención obstétrica, donde son ellas que poseen más chances de sufrir violencia obstétrica por el racismo institucional fijado en la sociedad, por la consecuencia de la trayectoria esclavista del país que tiene hasta los días actuales estos vestigios.
\end{abstract}

Palabras clave: Salud de la Mujer; Enfermería Obstétrica; Violencia contra la Mujer; Racismo; Violencia Obstétrica.

\section{Introdução}

A Organização Mundial de Saúde apresenta dados sobre a violência obstétrica por todo o mundo, mulheres vivenciam situações de maus-tratos, desrespeito, abusos, negligências, violação dos direitos humanos por profissionais de saúde, sendo mais frequentes durante a assistência ao parto e ao nascimento (Jardim \& Modena, 2018). "No Brasil, os debates em torno do 
Research, Society and Development, v. 11, n. 1, e46111125184, 2022

(CC BY 4.0) | ISSN 2525-3409 | DOI: http://dx.doi.org/10.33448/rsd-v11i1.25184

termo violência obstétrica começam a surgir nos primeiros anos da década de 2000, sobre as influências das experiências ocorridas na Venezuela e na Argentina" (Assis, 2018).

"O parto deve ser um momento de confiança e segurança entre profissional e paciente, é preciso enfatizar que toda mulher possui o direito a um atendimento descente e de qualidade durante toda a gestação, dispondo de informações adequadas, reduzindo assim, os riscos de violência obstétrica, e caso venham a sofrer, possam denunciar o profissional", é o que Silva et al. (2021) afirmam. De acordo com Lansky et al. (2021) "A violência obstétrica é considerada como violência de gênero, por se dirigir especificamente a mulheres e permear relações de poder desiguais na nossa sociedade".

"O parto e o nascimento, que eram vistos como um evento fisiológico e feminino, começam a ser encarados como um evento médico e masculino, incluindo a noção do risco e da patologia como regra, e não mais exceção" (Zanardo, Uribe, Nadal \& Habigzang, 2017). Os profissionais de saúde se vestem de uma autoridade técnico-científica e apoiando-se nas relações de poder e desigualdade entre as usuárias para manter a obediência às regras, gerando fragilidade nos vínculos de paciente e profissional, junto com crise de confiança no cuidado que é prestado, ocasionando perda na autonomia da mulher e seu livre direito de decisão sobre seu corpo (Jardim \& Modena, 2018).

Sena e Tesser (2017) referem que a violência obstétrica pode se apresentar através de discriminação social, negligência no atendimento, violência verbal, podendo ser tratamento grosseiro, gritos, humilhações intencionais, ameaças, violência física incluindo não oferecer medicação analgésica quando é indicado. Fazer intervenções, procedimentos desnecessários e uso inadequado de tecnologias frente a evidências científicas, que podem resultar em uma sequência de intervenções com sequelas e riscos, a violência obstétrica pode ser apresentar até através de abusos sexuais.

De acordo com Jardim e Modena (2018) "uma em cada quatro mulheres no Brasil sofreu algum tipo de violência obstétrica (VO) durante a assistência ao parto e, das que abortaram, metade também tinha relato semelhante". Tempesta e Eneile (2021) usam o termo racismo obstétrico para se referir a violência sofrida por mulheres negras durante o parto, dizendo que, “[...] é uma extensão da estratificação racial e está inscrito tanto na estigmatização historicamente construída das mulheres negras como nas lembranças de suas interações com médicos, enfermeiras e outros profissionais médicos".

Observando a saúde de mulheres negras sob a perspectiva étnico-social, é possível compreender a ligação do racismo como um determinante social que pode intervir diretamente no processo de saúde e doença. A população negra se torna mais vulnerável e tem mais chances de dificuldade no acesso aos serviços de saúde, por consequência da forma de organização das relações raciais no Brasil (Theophilo, Rattner \& Pereira, 2018). Tanto Oliveira como Kubiak (2019) afirmam que o racismo mesmo sendo nas suas formas mais explícitas proibido por lei, ainda assim se manifesta de formas variadas na sociedade, formando o comportamento das pessoas por estar na estrutura da sociedade, e o racismo institucional "[...] possui uma forma sutil de manifestação e se encontra implícito no funcionamento das instituições". Às necessidades de saúde da população negra são delimitadas desde a estruturação do Sistema Único de Saúde e na Política Nacional de Saúde Integral da População Negra (PNSIPN), oficializada em 2009. A PNSIPN reconhece a existência da relação entre racismo e vulnerabilidade em saúde da população negra, e ponta o racismo institucional na composição do cuidado e a carência de elaboração de ações (Borret et al., 2020).

A violência obstétrica pode ser compreendida como uma das possíveis causas da mortalidade materna. Através de pesquisas é possível observar que os números de mortalidade materna estão vinculados ao acesso e à qualidade de serviços de saúde oferecidos, pois a eficiência da aplicação das políticas de saúde poderia evitar essas mortes (Assis, 2018). Os profissionais de saúde têm o dever de prestar serviço pensado, avaliado e livre de discriminações e preconceitos, atentando-se apenas às necessidades e individualidade de cada mulher que esteja utilizando o sistema de saúde (Menezes, Reis, Sales, Jardim, \& Lopes, 2020). A Organização Mundial de Saúde destaca que a enfermagem obstétrica é a classe profissional mais 
qualificada para realizar a mudança na violência vem sendo praticada e firmar na assistência, a segurança no momento do parto e nascimento (Moura et al., 2019).

O Presente artigo teve como objetivo identificar a relação do racismo institucional com a violência obstétrica em mulheres negras.

\section{Metodologia}

Trata-se de uma revisão integrativa de literatura que seguiu as seis etapas indicadas para sua execução: seleção do tema e elaboração da pergunta norteadora; busca na literatura; coleta de dados; análise dos estudos incluídos; discussão do resultado e apresentação da Revisão Integrativa. A revisão reuniu de maneira sistemática e ordenada, os resultados de pesquisas relacionadas a violência obstétrica em mulheres negras no período de 2016 a 2021, mediante pesquisa bibliográfica eletrônica, realizada em novembro de 2021, utilizando as bases de dados, The Scientific Electronic Library Online (SciELO), Sistema Online de Busca e Análise de Literatura Médica (MEDLINE/PubMed) e Biblioteca Virtual de Saúde (BVS) a partir de periódicos indexados nas bases de dados LILACS, COLECIONA SUS, BDENF.

A revisão integrativa da literatura consiste na construção de uma análise ampla da literatura, contribuindo para discussões sobre métodos e resultados de pesquisas, assim como reflexões sobre a realização de futuros estudos. O propósito inicial deste método de pesquisa é obter um profundo entendimento de um determinado fenômeno baseando-se em estudos anteriores (Mendes, Silveira \& Galvão, 2008).

Foram incluídos artigos de pesquisa originais completos em português relacionados ao tema, artigos disponíveis online na íntegra e sem custo relacionados, e os critérios de exclusão abrangeram, artigos duplicados, sem resumo na base de dados e que não abordassem a temática do estudo. Foram empregados os seguintes descritores: "Violência obstétrica", "enfermagem obstétrica", "enfermagem" "mulheres negras" e "racismo institucional". Após a definição dos descritores aplicou-se o operador booleano AND para a realização dos cruzamentos entre descritores "Violência obstétrica" AND "mulheres negras", "Violência obstétrica" AND Enfermagem obstétrica" e "Racismo institucional" AND "Enfermagem".

O conjunto de buscas bibliográficas identificadas nas bases de dados foi organizado e aplicado em uma planilha Excel, para a seleção e análise por título, resumo e posteriormente em texto na íntegra. Todo o processo de identificação, seleção, exclusão e inclusão foi apresentado no fluxograma PRISMA (Figura1). 
Research, Society and Development, v. 11, n. 1, e46111125184, 2022

(CC BY 4.0) | ISSN 2525-3409 | DOI: http://dx.doi.org/10.33448/rsd-v11i1.25184

Figura 1 - Fluxograma do processo de busca e seleção.
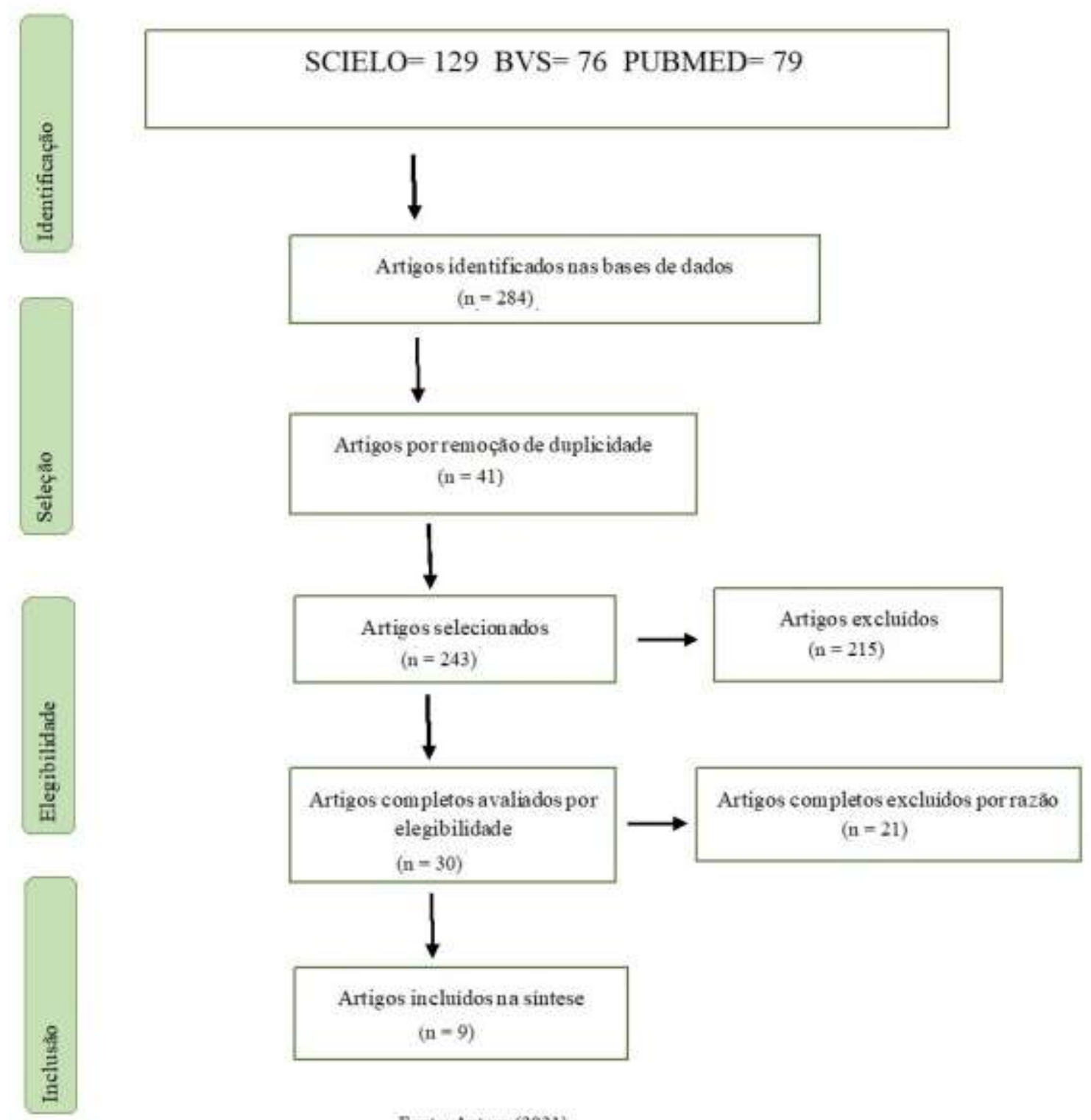

Fonte: Autora (2021)

Após leitura dos estudos selecionados, as informações deles foram sintetizadas em uma tabela, composta por: ano de publicação, título, autores, objetivos, resultados, e numeração para sua identificação, E1 até E9.

\section{Resultados e Discussão}

Os nove estudos selecionados foram publicados no Brasil entre os anos 2016 e 2020, sendo um relato de experiência, uma revisão bibliográfica, um estudo qualitativo descritivo, um estudo quati-qualitativo transversal descritivo, dois estudos transversais e três revisões integrativas. Não houve predominância de autores. 
Quadro 1 - Caracterização dos artigos selecionados na revisão.

\begin{tabular}{|c|c|c|c|}
\hline Número & $\begin{array}{c}\text { Título } \\
\text { Autores }\end{array}$ & $\begin{array}{l}\text { País } \\
\text { Ano }\end{array}$ & $\operatorname{Objetivos}(\mathbf{O})$ e $\operatorname{Resultados}(\mathbf{R})$ \\
\hline 1 & $\begin{array}{l}\text { "A violência obstétrica } \\
\text { praticada contra mulheres } \\
\text { negras no SUS" } \\
\text { Paula Land Curi; Mariana } \\
\text { Thomaz de Aquino Ribeiro; } \\
\text { Camilla Bonelli Marra. }\end{array}$ & $\begin{array}{l}\text { Brasil } \\
2020\end{array}$ & $\begin{array}{l}\text { O: Examina a violência obstétrica contra mulheres negras no Sistema Único de } \\
\text { Saúde (SUS), partindo de experiências de estágio e extensão universitária em } \\
\text { Psicologia, em maternidades públicas. } \\
\text { R: A violência obstétrica é um analisador das condições da (não) assistência } \\
\text { prestada às mulheres, em especial, às negras. Ela escancara não só como as } \\
\text { violências de gênero e raça interseccionadas operam nas e pelas instituições e } \\
\text { serviços de saúde, machistas e racistas, mas também as hierarquias reprodutivas, } \\
\text { historicamente construídas e cristalizadas, que impõem quem pode ser mãe, mas } \\
\text { também modos de acessar serviços e assistir bastante diferenciados. }\end{array}$ \\
\hline 2 & $\begin{array}{l}\text { "Interseccionalidade, racismo } \\
\text { institucional e direitos } \\
\text { humanos: compreensões à } \\
\text { violência obstétrica" } \\
\text { Jussara Francisca de Assis. }\end{array}$ & $\begin{array}{l}\text { Brasil } \\
2018\end{array}$ & $\begin{array}{l}\text { O: Trazer os conceitos interseccionalidade, racismo institucional e direitos } \\
\text { humanos para compreender a violência obstétrica relacionada às mulheres } \\
\text { negras na saúde } \\
\text { R: É possível supor a existência do viés racial na atenção às mulheres negras } \\
\text { em período gravídico puerperal, sendo necessário reconhecer o valor do recorte } \\
\text { étnico racial para a análise dos diferenciados serviços de saúde prestados à } \\
\text { população, como as maternidades. }\end{array}$ \\
\hline 3 & $\begin{array}{l}\text { "Raça e violência obstétrica no } \\
\text { Brasil" } \\
\text { Kelly Diogo de Lima. }\end{array}$ & $\begin{array}{l}\text { Brasil } \\
2016\end{array}$ & $\begin{array}{l}\text { O: Comparar as características sociodemográficas de mulheres segundo cor/, } \\
\text { com foco nas mulheres negras e analisar os tipos mais comuns de agressões a } \\
\text { elas infringidas na assistência ao parto pelo Sistema Único de Saúde. } \\
\text { R: Muitas das intervenções usadas na rotina de um parto são desnecessárias ou } \\
\text { mesmo prejudiciais à mulher, sendo assim, violentas. Profundas desigualdades } \\
\text { socioeconômicas entre as negras e indígenas quando comparadas ao grupo de } \\
\text { brancas. Dentre as violências realizadas contra as parturientes no momento do } \\
\text { parto conforme sua cor/raça os toques vaginais repetitivos tiveram maior } \\
\text { ocorrência em parda. }\end{array}$ \\
\hline 4 & $\begin{array}{l}\text { "Produção de conhecimento } \\
\text { sobre violência obstétrica: o } \\
\text { lado invisível do parto" } \\
\text { Adriana Loureiro da Cunha; } \\
\text { Rafaela Batista Lopes } \\
\text { Henriques; Thuane Rodrigues } \\
\text { Donato da Silva; Maria Regina } \\
\text { Bernardo da Silva; Kátia } \\
\text { Tertulliano; Halene Cristina } \\
\text { Dias de Armanda e Silva. }\end{array}$ & $\begin{array}{l}\text { Brasil } \\
2020\end{array}$ & $\begin{array}{l}\text { O: Conhecer através da revisão integrativa de literatura, a produção científica } \\
\text { sobre violência obstétrica. } \\
\text { R: Evidenciado como fator predominante a formação dos profissionais de saúde } \\
\text { e a negligência como parte estruturante no desenho atual da assistência, pelas } \\
\text { formas de violência verbal e violência física. }\end{array}$ \\
\hline 5 & $\begin{array}{l}\text { "A violência obstétrica na } \\
\text { percepção das multíparas" } \\
\text { Deise de Oliveira Ribeiro; } \\
\text { Giovana Calcagno Gomes; } \\
\text { Adriane Maria Netto de } \\
\text { Oliveira; Simone Quadros } \\
\text { Alvarez; Bruna Goulart } \\
\text { Gonçalves; Daniele Ferreira } \\
\text { Acosta. }\end{array}$ & $\begin{array}{l}\text { Brasil } \\
2020\end{array}$ & $\begin{array}{l}\text { O: Conhecer a percepção das multíparas acerca das suas experiências com a } \\
\text { violência obstétrica. } \\
\text { R: Violência Obstétrica quando primíparas, onde as mulheres sofriam violência } \\
\text { verbal para colaborarem com o período expulsivo do parto; Violência Obstétrica } \\
\text { quando multíparas, onde foi observada violência verbal e física, pautadas pelo } \\
\text { grande número de filhos que possuíam. }\end{array}$ \\
\hline
\end{tabular}




\begin{tabular}{|c|c|c|c|}
\hline 6 & $\begin{array}{l}\text { "Fatores associados à } \\
\text { humanização da assistência em } \\
\text { uma maternidade pública" } \\
\text { Ana Dorcas de Melo Inagaki; } \\
\text { Renata Julie Porto Leite Lopes; } \\
\text { Nadyege Pereira Cardoso; } \\
\text { Luana Meneses Feitosa; Ana } \\
\text { Cristina Freire Abud; Caíque } \\
\text { Jordan Nunes Ribeiro. }\end{array}$ & $\begin{array}{l}\text { Brasil } \\
2018\end{array}$ & $\begin{array}{l}\text { O: Identificar fatores associados à humanização da assistência durante o } \\
\text { trabalho de parto, parto e nascimento. } \\
\text { R: Houve associação significante entre a presença do acompanhante e liberdade } \\
\text { para fazer perguntas; baixa escolaridade e menor informação; parto vaginal e } \\
\text { desrespeito por parte dos profissionais; mulheres brancas e presença do } \\
\text { acompanhante com maior satisfação. }\end{array}$ \\
\hline 7 & $\begin{array}{l}\text { "Violência obstétrica: } \\
\text { influência da Exposição } \\
\text { Sentidos do Nascer na vivência } \\
\text { das gestantes" } \\
\text { Sônia Lansky; Kleyde Ventura } \\
\text { de Souza; Eliane Rezende de } \\
\text { Morais; Bernardo Jefferson } \\
\text { Oliveira; Carmen Simone Grilo } \\
\text { Diniz; Nayara Figueiredo } \\
\text { Vieira; Rosiane de Oliveira } \\
\text { Cunha; Amélia Augusta de } \\
\text { Lima Friche. }\end{array}$ & $\begin{array}{l}\text { Brasil } \\
2019\end{array}$ & $\begin{array}{l}\text { O: Analisar o perfil das gestantes que visitaram a Sentidos do Nascer, a sua } \\
\text { percepção sobre violência no parto e nascimento e os fatores socioeconômico- } \\
\text { demográficos e assistenciais associados ao relato de violência obstétrica. } \\
\text { R: Violência obstétrica foi reportada por } 12,6 \% \text { das mulheres e associada ao } \\
\text { estado civil, à menor renda, à ausência de companheiro, ao parto em posição } \\
\text { litotômica, à realização da manobra de Kristeller e à separação precoce do bebê } \\
\text { após o parto. Predominaram nos relatos de violência obstétrica: intervenção não } \\
\text { consentida/aceita com informações parciais, cuidado indigno/abuso verbal; } \\
\text { abuso físico; cuidado não confidencial/privativo e discriminação. A visita à } \\
\text { exposição aumentou o conhecimento das gestantes sobre violência obstétrica. } \\
\text { Entretanto, o reconhecimento de procedimentos obsoletos ou danosos na } \\
\text { assistência ao parto como violência obstétrica foi ainda baixo. Iniciativas como } \\
\text { esta podem contribuir para ampliar o conhecimento e a mobilização social sobre } \\
\text { as práticas na assistência ao parto e nascimento. }\end{array}$ \\
\hline 8 & $\begin{array}{l}\text { "A escolha da via de parto e a } \\
\text { autonomia das mulheres no } \\
\text { Brasil: uma revisão integrativa" } \\
\text { Nathalia Fernanda Fernandes da } \\
\text { Rocha; Jaqueline Ferreira }\end{array}$ & $\begin{array}{l}\text { Brasil } \\
2020\end{array}$ & $\begin{array}{l}\text { O: Apresentar e discutir quais os determinantes e como ocorre a escolha da via } \\
\text { de parto, levando em conta o direito de autonomia das mulheres. } \\
\text { R: Foram reveladas questões sobre pré-natal, ensino profissional, violência } \\
\text { obstétrica, tecnologia, direitos, modelos de atenção à saúde, taxa de } \\
\text { mortalidade, acesso, entre outros. }\end{array}$ \\
\hline 9 & $\begin{array}{l}\text { "Parirás na dor? Revisão } \\
\text { integrativa da violência } \\
\text { obstétrica em unidades públicas } \\
\text { brasileiras" } \\
\text { Aline de Carvalho Martins; } \\
\text { Geiza Martins Barros. }\end{array}$ & $\begin{array}{l}\text { Brasil } \\
2016\end{array}$ & $\begin{array}{l}\text { O: Proporcionar maior visibilidade às discussões acerca da violência obstétrica } \\
\text { sofrida por mulheres brasileiras nas instituições de saúde públicas. } \\
\text { R: Os tipos de violências obstétricas identificadas foram: violência } \\
\text { institucional, violência moral, violência física, violência sexual, violência } \\
\text { psicológica e verbal. }\end{array}$ \\
\hline
\end{tabular}

Fonte: Autores (2021).

As categorias de análise foram organizadas em duas, a primeira sendo denominada Histórico social da população negra e a segunda Competência do profissional de saúde defasada.

\section{Histórico social da população negra}

Quatro dos estudos abordam o histórico social da população negra como fatores que contribuem para a violência obstétrica em mulheres negras (estudos: Curi, Ribeiro \& Marra, 2020, Assis, 2018, Inagaki et al., 2018 e Martins \& Barros, 2016), eles reúnem opiniões e achados relacionados ao tratamento de mulheres negras ser negligenciado devido o passado escravocrata do país, a atual construção social e racismo institucional.

Curi, Ribeiro e Marra (2020) afirmam que especialmente no caso brasileiro, o Estado juntamente com a medicina e a igreja forjaram um dito "modelo de mulher", que é embasado na anatomia e fisiologia, porém junto com interesses morais, 
políticos, populacionais e econômicos, o que resultou em formas diferentes de olhar os corpos femininos, pois, corpos brancos e negros sempre foram vistos de formas diferentes nesse país com histórico de escravidão. A natureza racial implícita que faz uma sugestão de racismo institucional e o sexismo moldam uma rede de complexidades que tem no espaço das unidades de saúde uma dinâmica cheia de conflitos (Assis, 2018). Para Curi, Ribeiro e Marra (2020), a ciência, teve e tem a até os dias atuais participação ativa na construção do racismo no Brasil, criando a ideia de superioridade e inferioridade de raças, sendo as mulheres negras as mais estereotipadas, excluídas, aquelas que sempre "suportam mais dor", de acordo com princípios racistas disfarçados em princípios científicos, são as que mais sofrem violências, por suportarem mais, não recebem anestesia ou recebem demais, são as que mais morrem.

Mulheres autodeclaradas brancas quando avaliam o atendimento obstétrico costumam sentir-se mais satisfeitas do que mulheres negras, afirmam Inigaki et al. (2018), e concluem que tal achado pode te relação com o histórico de desigualdade étnico-racial na assistência que é oferecida, onde mulheres não brancas são expostas a uma situação de vulnerabilidade, onde são violados o direito à saúde e acesso qualificado. Estudos evidenciam que a violência obstétrica não atinge todas igualmente, mulheres de baixo poder aquisitivo, negras, menos escolarizadas, que se queixam, não muito colaborativas, e que não tem fácil acesso aos serviços de saúde tem maior exposição a comportamentos violentos profissionais de saúde (Martins \& Barros, 2016). De acordo com Assis (2018) a resistência é parte intrínseca da identidade negra feminina, já que as experiências de desfavorecimento social, político, econômico e cultural vêm fazendo parte de seu cotidiano desde a travessia transatlântica. Sendo assim, a categoria mulher negra é histórica, e a luta contra as desigualdades que a permeiam é secular.

\section{Competência do profissional de saúde defasada}

Cinco dos artigos abordaram a competência do profissional de saúde defasada (estudos: Lima, 2016, Cunha et al., 2020, Ribeiro et al., 2020, Lasky et al., 2018 e Rocha \& Ferreira, 2020), reunindo afirmações a respeito da falta de preparo dos profissionais para prestar assistência adequada, reproduzindo estereótipos e achismos, ocasionando na violência obstétrica, assim os profissionais de saúde, muitas vezes no lugar de promover a saúde se tornam agentes de violência.

A violência obstétrica está situada entre a institucional e a de gênero, conforme é praticada nos serviços de saúde, por ação e omissão, dirigida à mulher, a afetando no seu emocional e em seu físico, aumentando a naturalização da sua subordinação na sociedade, diz Lima (2016) e a partir disso acrescenta que, é possível compreender que a violência obstétrica não é consequência de um modelo biomédico, mecanicista e hegemônico, mas justamente constitutivo dele. As classes profissionais que mais promovem a violência obstétrica são os médicos e enfermeiros, entre as ações no momento do parto mais relatados em estudos pelas mulheres estão: o uso de expressões pejorativas, opressões, gritos e humilhações (Cunha et al., 2020). De acordo com Ribeiro et al. (2020), a violência obstétrica vem sendo banalizada, de forma discreta, naturalizada em atitudes tidas como "brincadeira" e falas ditas como "piadas" por profissionais de saúde, sendo até já esperado pelas pacientes, que socialmente, propagam essa realidade para outras mulheres, como algo corriqueiro do cotidiano.

$\mathrm{O}$ relato de violência obstétrica está relacionado a práticas assistenciais ultrapassadas, afetando as mulheres de maneira diferenciada no meio da sociedade brasileira, o que pode acarretar iniquidades na assistência ao parto e nascimento (Lasky et al., 2018). Para Rocha e Ferreira (2020), o impacto causado pela violência obstétrica pode ser micro ou macro, já que prejudica o vínculo paciente e profissional de saúde e o processo de promoção da saúde, ainda destacam que esse tipo de violência, não se trata de um problema de grupos pequenos ou de indivíduos treinados de forma inadequada, pois no meio dos profissionais de saúde essas práticas não são exceção.

Segundo Cunha et al. (2020), conhecimentos científicos sistematizados focados na saúde da mulher, são indicados para o combate à violência do tipo obstétrica, e os enfermeiros são fundamentais para a mudança do cenário atual de 
assistência, pois possuem a função de prestar cuidado, ensino e realizar pesquisas focadas nos cuidados gerais e específicos do indivíduo e sua família.

\section{Conclusão}

Os resultados e discussão apontam para a existência de uma maior vulnerabilidade das mulheres negras na assistência obstétrica, sendo elas mais suscetíveis a sofrer violência obstétrica em decorrência do racismo institucional instalado na sociedade, que é consequência do histórico escravocrata do país tendo até os dias atuais seus resquícios. Informações equivocadas sobre o corpo feminino negro, uma escala social de tratamento baseada na raça, e condutas dentro da área da saúde obsoletas que não focam na saúde da gestante negra e seu filho.

Observou-se também, a influência dos profissionais da saúde na perpetuação da violência obstétrica, sendo eles quem a reproduz diretamente, por vezes, a própria mulher pode não identificar ou reconhecer que alguma fala ou atitude se caracteriza como violência obstétrica, por falta de conhecimento do termo, sua definição ou pela banalização da violência como se fosse o modo correto de proceder. Os profissionais da saúde têm o dever de promover a saúde e bem-estar completo do paciente, os enfermeiros e médicos, são agentes ativos no parto e por consequência ao longo dos anos na propagação de práticas incorretas durante a assistência obstétrica, sendo assim, são indispensáveis para uma mudança na visão e atuação no processo de parir de mulheres negras.

Por fim, torna-se fundamental que sejam feitas analises a respeito do modo de atuação dos profissionais de saúde na assistência ao parto, principalmente de mulheres negras, pois através desta pesquisa, foi observado problemas relacionados a reprodução de preconceitos e ideais que se provam ultrapassadas. É importante que haja a atualização e desconstrução de técnicas obsoletas, não só na questão da medicina, mas também na questão social dentro dos hospitais e maternidades.

\section{Referências}

Assis, J. F. D. (2018). Interseccionalidade, racismo institucional e direitos humanos: compreensões à violência obstétrica. Serviço Social \& Sociedade, 547565. https://doi.org/10.1590/0101-6628.159.

Borret, R. H., Araujo, D. H. S. D., Belford, P. S., Oliveira, D. O. P. S. D., Vieira, R. C., \& Teixeira, D. S. (2020). Reflexões para uma Prática em Saúde Antirracista. Revista Brasileira de Educação Médica, 44. https://doi.org/10.1590/1981-5271v44.supl.1-20200405.

Curi, P. L., Ribeiro, M. T. D. A., \& Marra, C. B. (2020). A violência obstétrica praticada contra mulheres negras no SUS. Arquivos Brasileiros de Psicologia, 72(SPE), 156-169. http://dx.doi.org/10.36482/1809-5267.arbp2020v72s1p.156-169.

Cunha, A. L., Henriques, R. B. L., da Silva, T. R. D., da Silva, M. R. B., Tertulliano, K., \& de Armada, H. C. D. (2020). Produção de conhecimento sobre violência obstétrica: o lado invisível do parto. Nursing (São Paulo), 23(260), 3529-3532. https://doi.org/10.36489/nursing.2020v23i260p3529-3532.

Medeiros Moura, R. C., Pereira, T. F., Rebouças, F. J., de Medeiros Costa, C., Lernades, A. M. G., da Silva, L. K. A., \& da Rocha, K. D. M. M. (2018). Cuidados de enfermagem na prevenção da violência obstétrica. Enfermagem em Foco, 9(4). https://doi.org/10.21675/2357-707X.2018.v9.n4.1333.

Silva Melo, A., da Silva, S. B. S., da Costa, F. B., Barbosa, M. D. S. A., do Nascimento, K. C., \& dos Reis, R. P. (2020). Assistência de enfermagem frente à violência obstétrica: Um enfoque nos aspectos físicos e psicológicos. Brazilian Journal of Development, 6(10), 83635-83650. https://doi.org/10.34117/bjdv6n10-703.

Dias, R. L., Silva, A. A., Pereira, B. B., Pereira, J. D. S. C., de Azevedo, M. B., \& da Costa Gomes, S. K. (2015). Violência obstétrica: perspectiva da enfermagem. Revista Rede de Cuidados em Saúde, 9(2). http://publicacoes.unigranrio.edu.br/index.php/rcs/article/viewFile/2686/1318.

Inagaki, A. D. D. M., Lopes, R. J. P. L., Cardoso, N. P., Feitosa, L. M., Abud, A. C. F., \& Ribeiro, C. J. N. (2018). Fatores associados à humanização da assistência em uma maternidade pública. https://doi.org/10.5205/1981-8963-v12i7a231395p1879-1886-2018.

Jardim, D. M. B., \& Modena, C. M. (2018). Obstetric violence in the daily routine of care and its characteristics. Revista latino-americana de enfermagem, 26. http://dx.doi.org/10.1590/1518-8345.2450.3069.

Lansky, S., Souza, K. V. D., Peixoto, E. R. D. M., Oliveira, B. J., Diniz, C. S. G., Vieira, N. F., ... \& Friche, A. A. D. L. (2019). Violência obstétrica: influência da Exposição Sentidos do Nascer na vivência das gestantes. Ciência \& Saúde Coletiva, 24, 2811-2824. https://doi.org/10.1590/141381232018248.30102017 .

Lima, K. D. (2016). Raça e Violência Obstétrica no Brasil [monografia]. Recife: Centro de Pesquisas Aggeu Magalhães, Fundação Oswaldo Cruz. https://www.arca.fiocruz.br/bitstream/icict/18547/2/2016Lima\%2c\%20Kelly\%20Diogo.pdf. 
Research, Society and Development, v. 11, n. 1, e46111125184, 2022

(CC BY 4.0) | ISSN 2525-3409 | DOI: http://dx.doi.org/10.33448/rsd-v11i1.25184

Lima, S. T. B. (2020). DIREITOS HUMANOS DOS NEGROS: Racismo estrutural, necropolítica, interseccionalidade e o mito da democracia racial no Brasil. Revista Educação e Humanidades, 1(2, jul-dez), 119-132. https://periodicos.ufam.edu.br/index.php/reh/article/view/7917/5634.

Martins, A. D. C., \& Barros, G. M. (2016). Parirás na dor? Revisão integrativa da violência obstétrica em unidades públicas brasileiras. Revista Dor, 17, 215218. https://doi.org/10.5935/1806-0013.20160074.

Mendes, K. D. S., Silveira, R. C. D. C. P., \& Galvão, C. M. (2008). Revisão integrativa: método de pesquisa para a incorporação de evidências na saúde e na enfermagem. Texto \& contexto-enfermagem, 17, 758-764. https://doi.org/10.1590/S0104-07072008000400018.

Menezes, F. R. D., Reis, G. M. D., Sales, A. D. A. S., Jardim, D. M. B., \& Lopes, T. C. (2019). O olhar de residentes em Enfermagem Obstétrica para o contexto da violência obstétrica nas instituições. Interface-Comunicação, Saúde, Educação, 24, e180664. https://doi.org/10.1590/Interface.180664.

Pereira, J. S., \& Gonçalves, M. D. M. (2016). Violência obstétrica: ofensa à dignidade humana. Brazilian Journal of Surgery and Clinical Research, v. 15, p. 103-108. http://www.mastereditora.com.br/periodico/20160604_094136.pdf.

Ribeiro, D. D. O., Gomes, G. C., Oliveira, A. M. N. D., Alvarez, S. Q., Gonçalves, B. G., \& Acosta, D. F. (2020). A violência obstétrica na percepção das multíparas. Revista Gaúcha de Enfermagem, 41. https://doi.org/10.1590/1983-1447.2020.20190419.

Rocha, N. F. F. D., \& Ferreira, J. (2020). A escolha da via de parto e a autonomia das mulheres no Brasil: uma revisão integrativa. Saúde em Debate, 44, 556568. https://doi.org/10.1590/0103-1104202012521.

Sena, L. M., \& Tesser, C. D. (2016). Violência obstétrica no Brasil e o ciberativismo de mulheres mães: relato de duas experiências. Interface-Comunicação, Saúde, Educação, 21, 209-220. https://doi.org/10.1590/1807-57622015.0896.

da Silva, A. F. P., de Almeida, B. G. R. F., Ribeiro, E. A., Teixeira, L. C., da Silva, P. C. P. O. \& Ribeiro, A. S. (2021). Violência obstétrica relacionada a perda de autonomia da mulher na sala de parto. Research, Society and Development, 10(5), e 22210514814. http://dx.doi.org/10.33448/rsd-v10i5.14814.

Oliveira, B. M. C., \& Kubiak, F. (2019). Racismo institucional e a saúde da mulher negra: uma análise da produção científica brasileira. Saúde em Debate, 43, 939-948. https://doi.org/10.1590/0103-1104201912222.

Tempesta, G. A., \& Eneile, M. (2021). Racismo obstétrico: a política racial da gravidez, do parto e do nascimento. Amazônica-Revista de Antropologia, 12(2), 751-778. http://dx.doi.org/10.18542/amazonica.v12i2.9194.

Theophilo, R. L., Rattner, D., \& Pereira, É. L. (2018). Vulnerabilidade de mulheres negras na atenção ao pré-natal e ao parto no SUS: análise da pesquisa da Ouvidoria Ativa. Ciência \& Saúde Coletiva, 23, 3505-3516. https://doi.org/10.1590/1413-812320182311.31552016.

Zanardo, G. L. D. P., Uribe, M. C., Nadal, A. H. R. D., \& Habigzang, L. F. (2017). Violência obstétrica no Brasil: uma revisão narrativa. Psicologia \& sociedade, 29. https://doi.org/10.1590/1807-0310/2017v29155043. 